\title{
Internal carotid artery injury during endonasal sinus surgery: our experience and review of the literature
}

\author{
Rottura dell'arteria carotide interna durante la chirurgia nasale endoscopica: \\ nostra esperienza e review della letteratura
}

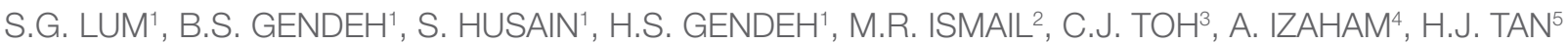 \\ ${ }^{1}$ Department of Otorhinolaryngology, Head and Neck Surgery, Universiti Kebangsaan Malaysia Medical Centre \\ (UKMMC), Kuala Lumpur, Malaysia; ${ }^{2}$ Department of Radiology, UKMMC, Kuala Lumpur, Malaysia; ${ }^{3}$ Neurosurgery \\ Unit, Department of Surgery, UKMMC, Kuala Lumpur, Malaysia; ${ }^{4}$ Department of Anaesthesiology, UKMMC, Kuala \\ Lumpur, Malaysia; ${ }^{5}$ Neurology Unit, Department of Medicine, UKMMC, Kuala Lumpur, Malaysia
}

\section{SUMMMARY}

Iatrogenic internal carotid artery injury is a catastrophic but uncommon complication of endonasal sinus surgery. We present our experience in managing this emergency situation. A 52-year-old man underwent revision endoscopic repair of recurrent cerebrospinal fluid leak that was complicated with profuse haemorrhage during removal of the anterior wall of sphenoid sinus using a Hajek sphenoid punch forceps. Immediate packing of the sphenoid sinus controlled the haemorrhage. Urgent angiography revealed injury at the paraclival segment of the left internal carotid artery. An endovascular stent was initially placed but thrombosed; it was subsequently converted to coil embolisation. The patient had watershed cerebral infarct with hemiparesis post procedure but made full recovery within 6 weeks. Immediate nasal packing followed by urgent angiography and endovascular stent placement is the least invasive definitive treatment. If stenting is unsuccessful, endovascular balloon occlusion or coil embolisation is the next preferred treatment, if there is adequate cross-cerebral circulation. The success of treatment relies on its immediate management by a multidisciplinary team.

KEY WORDS: Internal carotid artery injuries • Endoscopy sphenoid sinus • Endovascular procedures • Angiography

\section{RIASSUNTO}

La rottura iatrogena dell'arteria carotide interna è una complicanza catastrofica, sebbene non frequente, della chirurgia endoscopica nasale. In questo lavoro presentiamo la nostra esperienza nella gestione di questa emergenza. Un uomo di 52 anni è stato sottoposto ad intervento di chiusura di fistola rinoliquorale, e durante l'intervento si è verificata una copiosa emorragia durante l'apertura, mediante pinza sfenoidale di Hajek, della parete anteriore del seno sfenoidale. L'immediato tamponamento del seno sfenoidale ha controllato l'emorragia. Mediante l'esecuzione di un'angiografia urgente, è stato individuato un punto di rottura della carotide interna sinistra a livello del segmento paraclivale. Quindi inizialmente è stato posizionato uno stent, ma si è trombizzato; successivamente è stata utilizzata una spirale endovascolare. Il paziente è andato incontro ad ischemia cerebrale con emiparesi post-procedura, che si è risolta del tutto nel giro di 6 settimane. Il tamponamento nasale seguito da un'angiografia in urgenza e il posizionamento di uno stent endovascolare possono rappresentare il trattamento definitivo meno invasivo. Se lo stent non dovesse avere successo, l'occlusione mediante balloon endovascolare o l'embolizzazione mediante spirale dovrebbero essere i trattamenti di scelta quando la rivascolarizzazione dai distretti controlaterali è garantita. Il successo del trattamento si basa soprattutto sull'immediatezza della gestione da parte di un team multidisciplinare.

PAROLE CHIAVE: Rottura dell'arteria carotide interna $\bullet$ Endoscopia seno sfenoidale $\bullet$ Procedure endovascolari $\bullet$ Angiografia

\section{Introduction}

An endoscopic approach to the paranasal sinuses has become standard surgical practice compared to traditional external approaches over the past three decades. It is generally a safe procedure, but severe complications may occur. Injury to the internal carotid artery (ICA) is one of the most feared and dreadful situations faced by the otorhinolaryngologist and skull base surgeons. Internal carotid artery injury during endonasal sinus surgery (ESS) is rare with an incidence that varies from $0 \%$ to $0.1 \%{ }^{1}$. May et al. reviewed a total of 4,691 patients and found only one case of intraoperative ICA injury ${ }^{2}$. Weidenbecher et al. experienced four cases of ICA injury following sphenoidectomy out of 16,000 endoscopic sinus procedures performed over 30 years period ${ }^{3}$. Despite the low reported incidence, the increasing prevalence of patients undergoing ESS makes understanding of the management of ICA 
injury essential for otorhinolaryngologists. In the event of occurrence of ICA injury, well-preparedness and immediate management may reduce morbidity, thus preventing mortality. Close collaboration of a multidisciplinary team comprising of otorhinolaryngologist, neurosurgeon, interventional radiologist, anaesthesiologist, ophthalmologist, neurologist and rehabilitation team is of utmost importance in the management of ICA injury. However, current literature review revealed no concise standard guidelines on the emergency management of ICA injury during ESS. We report an uncommon case of injury to paraclival segment of ICA during revision endoscopic repair of cerebrospinal fluid (CSF) leak and share our experience in its emergency management.

\section{Case report}

A 52-year-old man of Chinese ethnicity, who had endoscopic repair for right CSF fistula due to encephalocele eight years prior, presented with recurrent CSF leak on the ipsilateral side (Fig. 1) and underwent revision endoscopic repair under general anaesthesia. Leak was observed from previous site at lateral recess of right sphenoid sinus. A left Hadad's flap was raised and postero-superior septectomy was performed. While removing the anterior wall of sphenoid sinus using Hajek sphenoid punch forceps, it jerked posteriorly and impacted on the left intersinus septum that was attached to the left ICA canal, resulting in major haemorrhage. The surgical field was cleared of one

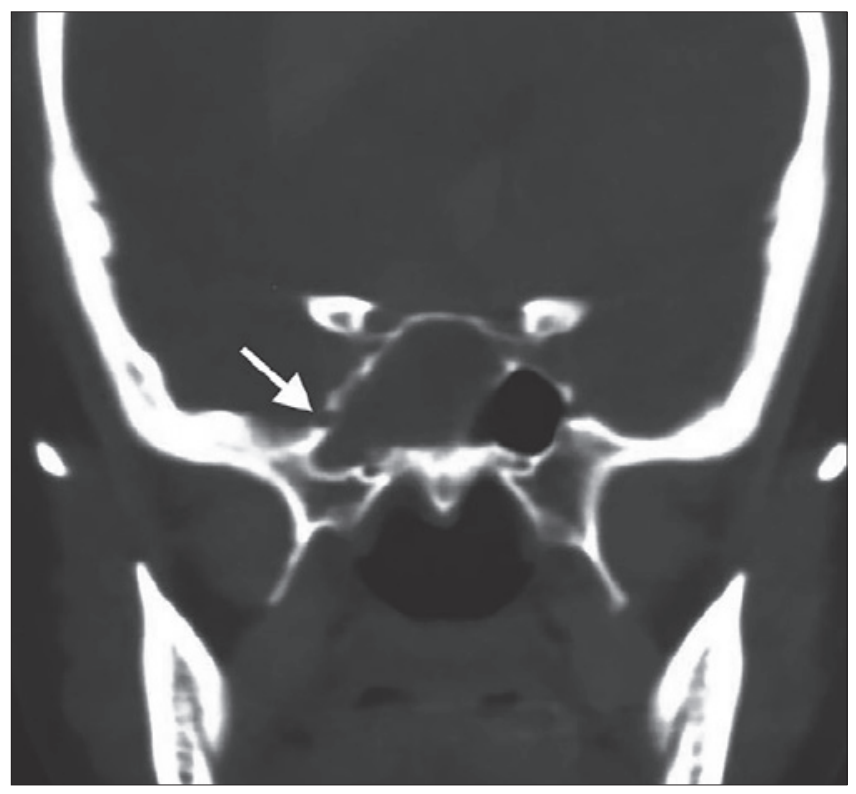

Fig. 1. Coronal CT image showing a bony defect at the lateral recess of right sphenoid sinus with soft tissue density in the right sphenoid sinus. litre of blood with large bore suction catheter followed by immediate packing of sphenoid sinus with ribbon gauze, which controlled the bleeding.

Upon discussion with the neurosurgeon and interventional neuroradiologist, the patient was immediately sent to the angiography suite on suspicion of ICA injury. Carotid angiography revealed injury to paraclival portion of left ICA with significant flow limitation to the left middle cerebral artery (MCA). There was no evidence of pseudo-aneurysm or carotid-cavernous fistula (Fig. 2a). Endovascular placement of a detachable stent (Solitaire $6 \mathrm{~mm}$ x $30 \mathrm{~mm}$ ) was performed (Fig. 2b) and blood flow to left MCA improved post-stenting, but unfortunately thrombosed within 15 minutes (Fig. 2c) and was thus removed. Control run angiography showed significant bleeding from the injured segment. After multidisciplinary discussion, the decision was made to sacrifice the left ICA. Balloon occlusion test (BOT) showed satisfactory cross flow from the contralateral right ICA and vertebral arteries to left cerebral hemisphere (Fig. 2d). Twelve coils (size ranging 3-8 mm) were deployed endoscopically proximal and distal to the ICA laceration site, preserving the posterior communicating artery and ophthalmic artery. Angiography post coiling showed complete occlusion of the left ICA and leakage sealed from the injured site (Fig. 2e). There was reconstitution of the left ophthalmic arterial flow from the collateral facial artery (Fig. 2f).

Throughout the procedure, the airway was secured by endotracheal intubation. The anaesthesiologist resuscitated and closely monitored haemodynamic status to maintain optimal cerebral circulation by keeping the blood pressure normotensive with mean arterial pressure (MAP) of $60 \mathrm{mmHg}$. The systolic blood pressure postsurgery was kept between 140-160 mmHg with MAP of 90-100 $\mathrm{mmHg}$ to ensure adequate cerebral perfusion. Haemoglobin dropped to $11.2 \mathrm{~g} / \mathrm{dL}$ post-surgery from baseline of $14.7 \mathrm{~g} / \mathrm{dL}$ and two units of packed erythrocytes were transfused to replace blood loss.

Cerebral MRI 12 hours postsurgery revealed multifocal infarcts along the watershed area involving the cortical and internal border zones of anterior and middle cerebral arteries. On the second day postsurgery, right hemiparesis with expressive dysphasia was observed. He was co-managed by neurologist and commenced oral aspirin $150 \mathrm{mg}$ daily. There was no visual impairment or evidence of ischaemic optic neuropathy. He underwent intensive rehabilitation and subsequently recovered with minimal residual right-sided weakness upon discharge at day 12 , which completely resolved at 6 weeks follow-up. He remained asymptomatic at 15 months follow-up, with no evidence of recurrent CSF leak or epistaxis. 


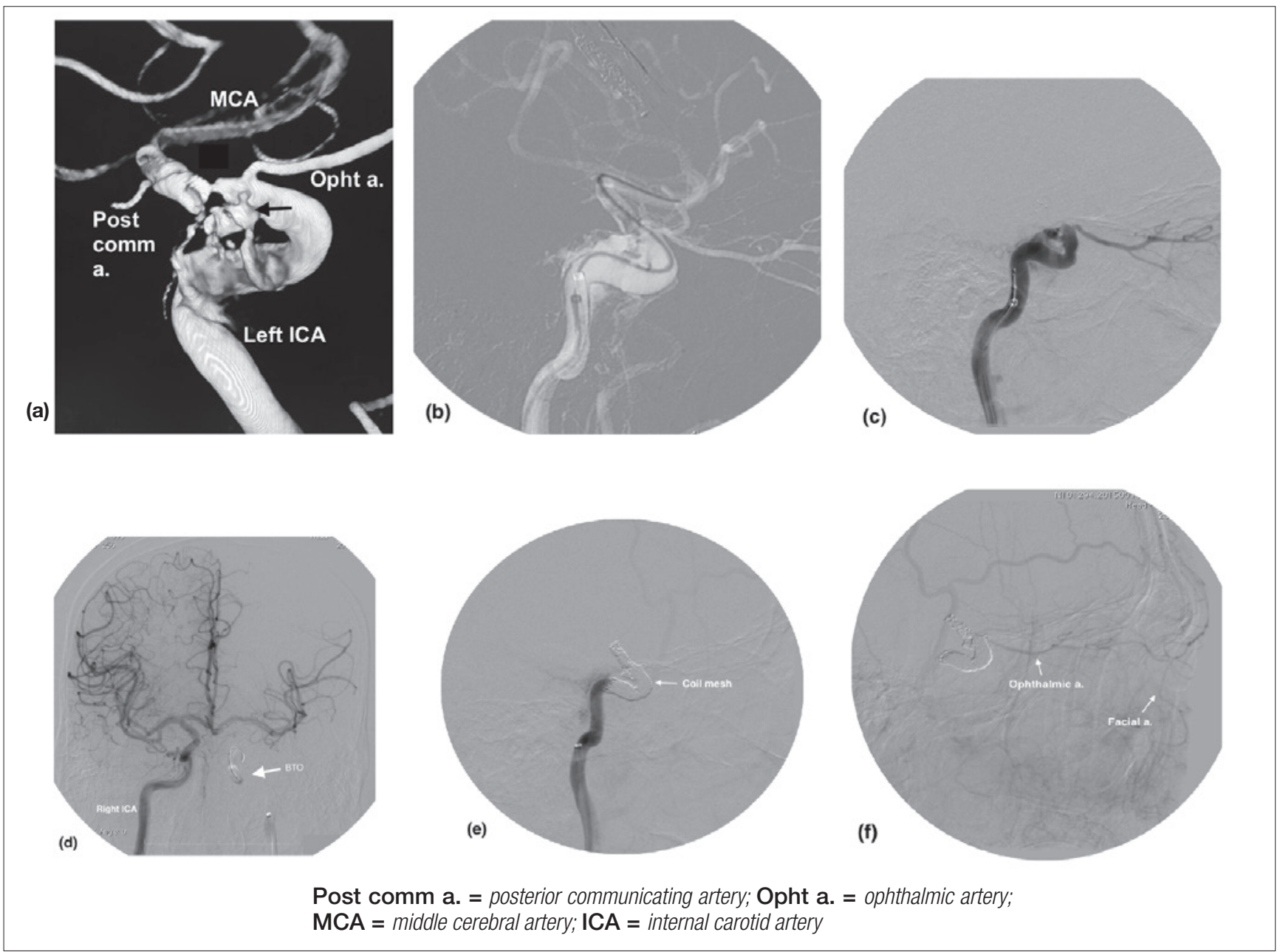

Fig. 2. a) 3D rotational angiogram reveals irregular outline at the posterior border of the left ICA (black arrow), with active extravasation of contrast media, and flow limitation to middle cerebral artery (MCA); b) micro-catheter crossing the injured portion of ICA before stenting; c) complete obliteration of the left ICA distal to the ophthalmic artery post endovascular stenting due to stent thrombosis; d) balloon occlusion test (BOT) of left ICA reveals satisfactory cross flow from right ICA to the left cerebral hemisphere, via anterior communicating artery and left posterior communicating artery; e) coil mesh in the injured portion of left ICA with complete obliteration of distal ICA. No extravasation of contrast media; f) reconstitution of left ophthalmic artery from facial artery collateral.

\section{Discussion}

Reported major complication rates of ESS have reduced significantly from $1.3-9.3 \%$ in 1980 's to $0.3-0.9 \%$ since the early 1990's due to improvement in nasal endoscopy and introduction of powered instruments ${ }^{4}$. Revision ESS is often considered to have an increased risk of complications due to altered anatomy and scarring. We experienced only one case of intraoperative ICA injury out of 4,507 patients who underwent ESS at our tertiary referral centre at UKM Medical Centre, Kuala Lumpur. This is consistent with the incidence reported in the literature ${ }^{23}$.

Injury to the ICA most frequently occurs during sphenoid sinus surgery, as the ICA lies directly adjacent to its lateral wall. Thus, understanding the anatomy of the ICA in relation to sphenoid sinus reduces the risk for operative complications during sphenoidotomy. Cadaveric studies discovered that $88 \%$ of the lateral sphenoid wall overlying the ICA is less than $0.5 \mathrm{~mm}$ thick, and dehiscent in 4-8\% of cases; $71 \%$ of the ICA bulges into the sphenoid sinus, up to $4 \mathrm{~mm}$ from the midline in $10 \%$ of cases ${ }^{5}$. Some authors observed that the bony inter-sphenoidal septum inserts onto the ICA canal wall in $16.3 \%$ of occasions ${ }^{6}$. Grasping and twisting the intersinus septum can therefore cause forced transmission to the attachment on the carotid canal, resulting in carotid artery avulsion or development of pseudo-aneurysm. Risk is reduced if removal of intersphenoidal septum is done using a cutting instrument or diamond drill. In our patient, it is likely that the Hajek sphenoid punch jerked and impacted posteriorly on the 
left intersinus septum (which attaches to the ipsilateral ICA canal) resulting in massive haemorrhage.

Most complications during ESS, e.g. orbital injury or CSF leak, occur more frequently on the right side. However, ICA injuries were reported more commonly on the left (ratio 1.3:1) ${ }^{7}$. The cavernous segment was the most commonly injured due to its anatomic proximity with the sphenoid sinus. Other factors that have been suggested to increase the likelihood of injuring the ICA during ESS include surgeon's right hand dominance, involvement of vascular structures, type of instrumentation, revision surgeries and preoperative vascular malformations.

Intra-operative ICA laceration is an emergency, with high flow and high pressure haemorrhage obscuring the surgical field, which may rapidly result in exsanguination of the patient. It is essential to be well prepared prior to the surgery to prevent delay in immediate management. The traditional method of emergency surgical ligation of carotid artery is often associated with a high incidence of complications such as death and stroke, which will also block endovascular access to the site of injury ${ }^{8}$. With increasing accessibility of endovascular intervention, surgical ligation should be considered as last resort to secure bleeding.

With adaptation of the protocols suggested by Pepper et al., we proposed a modified algorithm for emergency management of intraoperative ICA injury (Fig. 3) ${ }^{9}$. Any torrential bleeding especially during sphenoid sinus exploration should be suspected to originate from the ICA. However, controlling the high pressure haemorrhage from ICA within the confine of the nasal cavity can be extremely difficult. The first step to control the haemorrhage is adequate nasal packing. Various packing agents have been described in the literature, but gauze is the most frequently used due to its availability and ease of use ${ }^{1}$. In our case, the haemorrhage was successfully controlled with packing of sphenoid sinus with ribbon gauze, allowing the patient to be immediately transferred to the angiography suite for further investigation and treatment. While potentially lifesaving, nasal packing can also cause harm. Packing materials should ideally be placed with just enough force to control the haemorrhage, but not to occlude vascular flow. Raymond et al. reported cases of ICA occlusion and carotid stenosis secondary to over-packing ${ }^{10}$. It is still controversial whether concomitant carotid artery compression is beneficial. Few authors recommended ipsilateral common carotid artery compression to reduce bleeding, but the effect is limited because of good collateralisation and contralateral compensation ${ }^{811}$. Weidenbecher et al. advocated bilateral carotid artery compression, limited to two minutes, to facilitate packing of sphenoid sinus ${ }^{3}$.
The surgeon should work in close collaboration with the anaesthesiologist during the event of ICA injury. Where the surgeon attempts to control the intraoperative haemorrhage, the latter stabilises the patient's haemodynamic status simultaneously. The airway should be secured by endotracheal intubation if not already done. Blood grouping and cross match should be performed instantly and transfused if necessary. Lippert et al. suggested that head elevation and controlled hypotension reduces the haemorrhage, but is unnecessary given the significant hypotension that will result from massive bleeding ${ }^{11}$. Moreover, patients undergoing ESS are positioned in a reverse Trendelenburg and head tilt position before commencing surgery. It is now widely recommended that normo-tension be maintained through resuscitative measures to preserve adequate cerebral circulation ${ }^{1}$.

Once the patient has been stabilised and the haemorrhage is controlled, urgent transfer to angiography suite is essential to localise the site of haemorrhage and subsequent neuro-radiological endovascular intervention. If an endovascular facility is not available, transportation to a neuro-interventional centre has to be organised immediately. It is important to recognise that arterial injury may not be apparent in early angiography due to tight nasal packing. In a case reported by Koitschev et al., the initial angiography was normal but massive epistaxis recurred four days later upon removal of nasal packing. Repeated angiography revealed ICA laceration at infra-ophthalmic segment with traumatic carotid-cavernous fistula formation $^{8}$. Therefore, we suggest that if no vessel abnormality is identified during angiography with tight nasal packing, it should be carefully loosened followed by repeat angiography, which may enable a tamponed bleeding source to be identified.

A variety of therapeutic options are now available to the interventional radiologist to treat ICA injury, including balloon occlusion, coil embolisation and stent placement. Endovascular stenting has the advantage of closing the arterial leakage while maintaining lumen patency. However, it also has limitations as reported in two cases by Koitschev et al., in which endovascular repair with preservation of ICA were not possible due to extended laceration of the vessel wall and a direct communication to sphenoid sinus ${ }^{8}$. There is currently lack of international consensus on the preferred method of endovascular treatment.

Sufficient collateral arterial supply from the contralateral ICA must be confirmed by BOT if vessel occlusion is planned. Several authors have suggested that all patients should have a trial of stent placement, and only undergo embolisation if stenting fails. In the case that ICA occlu- 


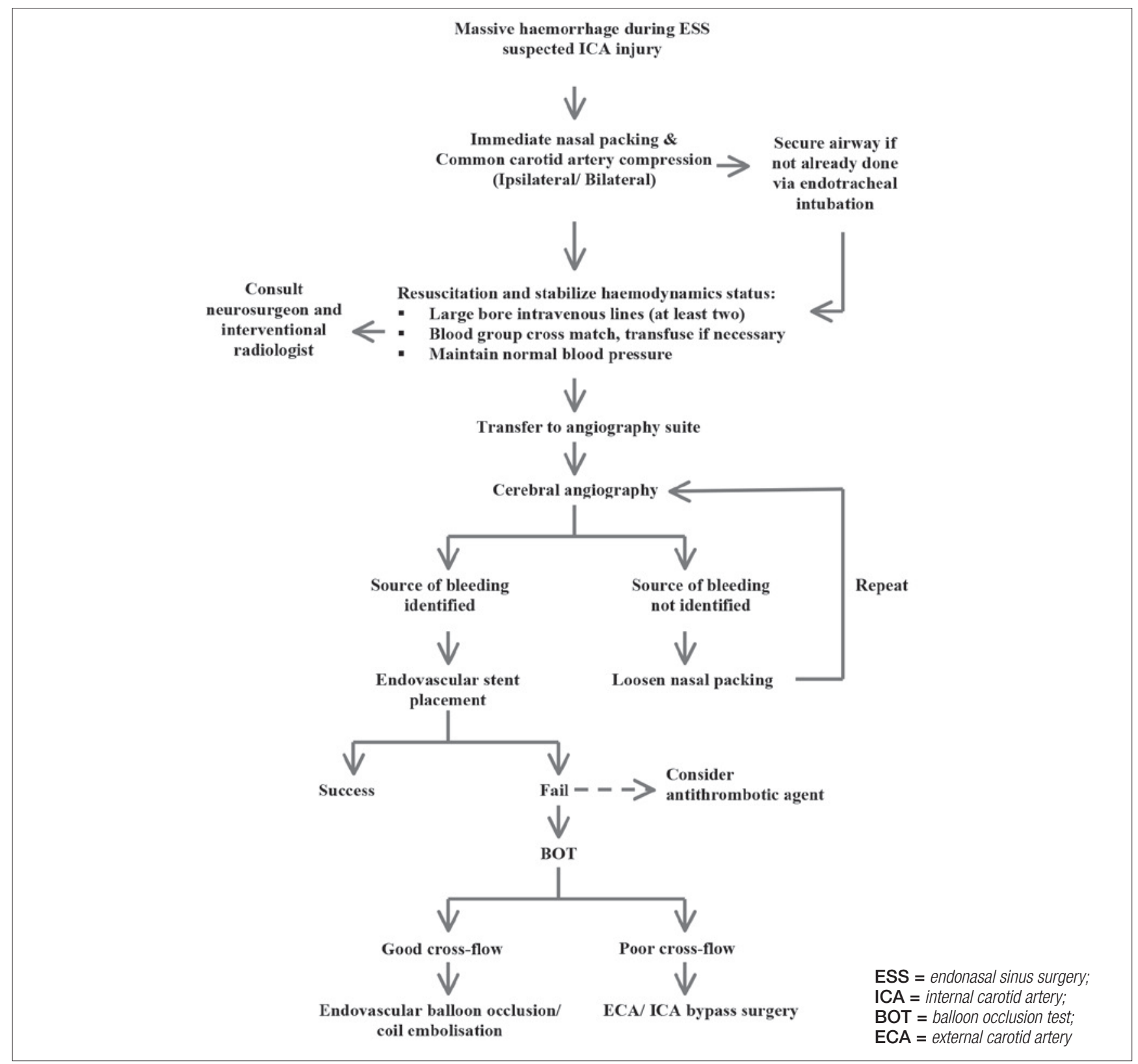

Fig. 3. Algorithm for emergency management of ICA injury during ESS.

sion is not tolerated, bypass surgery is required ${ }^{12}$. Other authors recommended endovascular balloon occlusion or coil embolisation as first line options in all patients with adequate collateral blood flow. However, even with a normal BOT there is still a 5-10\% risk of delayed infarction after therapeutic carotid artery occlusion, $4.7 \%$ of whom developed a permanent stroke ${ }^{13}$. It is commonly accepted that cerebral artery bypass surgery by an external approach is associated with a high complication rate and has no longer been described in the recent literature. Our case was special in terms of a complication (ICA stent thrombosis) that occurred within another complication (ICA injury), and we eventually had to sacrifice the patency of the ICA. The patient had watershed cerebral infarct postprocedure but made full recovery following intensive rehabilitation.

Besides endovascular intervention, several authors advocated endonasal closure of the carotid defect in sphenoid sinus with the use of autologous muscle-fascia patch or allogenous dura ${ }^{314}$. Animal model studies demonstrated 
that a muscle patch was effective at achieving haemostasis with ICA injuries less than 3-4 mm, but incomplete with continuous bleeding in larger lacerations ${ }^{15}$. According to past reports, three of four cases treated with muscle-fascia patch as first line emergency treatment were complicated with delayed pseudo-aneurysm formation, which required either a return to the operating theatre for trans-cranial clipping of pseudo-aneurysm, endovascular coiling of pseudo-aneurysm or balloon occlusion of ICA ${ }^{316}$. It must be recognised that not all injuries at the carotid arterial wall lie in direct contact with lateral sphenoid sinus wall, and a potential space may present in between. Thus, packing the sphenoid sinus may reduce the bleeding into sphenoid sinus giving a false impression to the surgeon that the haemorrhage has been controlled, but the bleeding from lacerated carotid artery may continue intra-cranially. One patient who was treated with bone wax and allegenous dura packing of sphenoid sinus died due to unrecognised subarachnoid haemorrhage with intra-ventricular extension ${ }^{14}$.

There is risk of thromboembolic events or stent thrombosis following endovascular occlusion or stenting, and a $4.4 \%$ risk of stroke within the first 30 days following carotid stent placement has been reported ${ }^{17}$. Antiplatelet and anticoagulant treatment is recommended before endovascular intervention, especially stenting, but there is no international consensus on the drug regime, time to initiate and duration of therapy. The rate of thromboembolic complications decreases significantly from $20 \%$ to $1.9 \%$ if antiplatelet therapy was initiated three days prior to stenting ${ }^{18}$. This prophylaxis, however, may not be an ideal option in an emergency situation of ICA injury on top of a haemodynamically compromised patient. There is a report of total vessel occlusion upon ICA stent insertion, but the thrombosis was completely resolved upon administrating intravenous heparin and glycoprotein IIb/ IIIa receptor antagonist ${ }^{19}$. Retrospectively, our patient whom had no antiplatelet therapy or heparin prior or during procedure could have his initial ICA stent salvaged upon administration of intravenous heparin and appropriate antiplatelet therapy, thus avoiding subsequent ICA coiling.

\section{Conclusions}

This case report highlights several learning points in the emergency management of ICA injury. Nasal packing with concurrent rapid resuscitation is often the first step to achieve haemostasis, followed by immediate cerebral angiography for diagnosis and treatment. Endovascular intervention is the first line definitive treatment, ideally preserving the ICA patency. Assessment of collateral cerebral blood flow must be performed and confirmed if the carotid artery is to be sacrificed. We describe a complicated case in which the endovascular stent was placed but thrombosed, and subsequently converted to coil embolisation. Post-operative care and subsequent intensive rehabilitation is important to expedite the recovery if the patient develops neurologic complications. The success of effective treatment of iatrogenic ICA injury depends on its prompt multidisciplinary management.

\section{Acknowledgements}

We thank Professor Dr. Srijit Das, from the Faculty of Medicine, University Kebangsaan Malaysia (UKM), Kuala Lumpur for his insightful suggestions and proofreading.

\section{Conflict of interest statement}

None declared.

\section{References}

1 Valentine R, Wormald PJ. Carotid artery injury after endonasal surgery. Otolaryngol Clin North Am 2011;44:1059-79.

2 May M, Levine HL, Mester SJ, et al. Complications of endoscopic sinus surgery: Analysis of 2108 patients - incidence and prevention. Laryngoscope 1994;104:1080-3.

3 Weidenbecher M, Huk WJ, Iro H. Internal carotid artery injury during functional endoscopic sinus surgery and its management. Eur Arch Otorhinolaryngol 2005;262:640-5.

4 Suzuki S, Yasunaga H, Matsui H, et al. Complication rates after functional endoscopic sinus surgery: analysis of 50,734 Japanese patients. Laryngoscope 2015;125:1785-91.

5 Fujii K, Chambers SM, Rhoton AL Jr. Neurovascular relationships of the sphenoid sinus. A microsurgical study. J Neurosurg 1979;50:31-9.

6 Park AH, Stankiewicz JA, Chow J, et al. A protocol for management of a catastrophic complication of functional endoscopic sinus surgery: internal carotid artery injury. Am J Rhinol 1998;12:153-8.

7 Chin OY, Ghosh R, Fang CH, et al. Internal carotid artery injury in endoscopic endonasal surgery: a systemic review. Laryngoscope 2016;126:582-90.

8 Koitschev A, Simon C, Lowenheim H, et al. Management and outcome after internal carotid artery laceration during surgery of the paranasal sinuses. Acta Otolaryngol 2006;126:730-8.

9 Pepper JP, Wadhwa AK, Tsai F, et al. Cavernous carotid injury during functional endoscopic sinus surgery: case presentations and guidelines for optimal management. Am J Rhinol 2007;21:105-9.

10 Raymond J, Hardy J, Czepko R, et al. Arterial injuries in transsphenoidal surgery for pituitary adenoma; the role of angiography and endovascular treatment. Am J Neuroradiol 1997;18:655-65.

11 Lippert BM, Ringel K, Stoeter P, et al. Stentgraft-implantation for treatment of internal carotid artery injury during endonasal sinus surgery. Am J Rhinol 2007;21:520-4.

12 Kassam A, Snyderman CH, Carrau RL, et al. Endoneurosurgical 
hemostasis techniques: lessons learned from 400 cases. Neurosurg Focus 2005;19:E7.

13 Mathis JM, Barr JD, Jungreis CA, et al. Temporary balloon test occlusion of the internal carotid artery: experience in 500 cases. Am J Neuroradiol 1995;16:749-54.

14 Weber R, Draf W, Keerl R, et al. Endonasal microendoscopic pansinus-operation in chronic sinusitis II. Results and complications. Am J Otolaryngol 1997;18:247-53.

15 Valentine R, Wormald PJ. Controlling the surgical field during a large endoscopic vascular injury. Laryngoscope 2011;121:562-6.

16 Buerke B, Tombach B, Stoll W, et al. Magnetic resonance angi- ography follow-up examinations to detect iatrogenic pseudoaneurysms following otorhinolaryngological surgery. J Laryngol Otol 2007;121:698-701.

17 Wholey MH, Jarmolowski CR, Eles G, et al. Endovascular stents for carotid artery occlusive disease. J Endovasc Surg 1997;4:326-38.

18 Lehmann P, Saliou G, Page C, et al. Epistaxis revealing the rupture of a carotid aneurysm of the cavernous sinus extending into the sphenoid: treatment using an uncovered stent and coils. Review of literature. Eur Arch Otorhinolaryngol 2009;266:767-72.

19 Tong FC, Cloft HJ, Joseph GJ, et al. Abciximab rescue in acute carotid stent thrombosis. Am J Neuroradiol 2000;21:1750-2.

Received: July 17, 2016 - Accepted: October 5, 2017

How to cite this article: Lum SG, Gendeh BS, Husain S, et al. Internal carotid artery injury during endonasal sinus surgery: our experience and review of the literature. Acta Otorhinolaryngol Ital 2019;39:130-136. https://doi.org/10.14639/0392-100X-1312

Address for correspondence: Balwant Singh Gendeh, Department of Otorhinolaryngology Head and Neck Surgery, Universiti Kebangsaan Malaysia Medical Centre, Jalan Yaacob Latiff, Bandar Tun Razak, 56000 Cheras, Kuala Lumpur, Malaysia. Tel. +60 391456047. Fax +60 391456675. E-mail: bsgendeh@gmail.com 